We thank the consultant obstetricians at the Liverpool Maternity Hospital who allowed us to study patients under their care.

\section{References} \\ 1 Anderson, W J R, fournal of Obstetrics and Gynaecology of the British \\ Empire, 1956, 63, 205. \\ 2 Seski, A G, and Millar, L A, Obstetrics and Gynaecology, 1963, 22, 227.
}

${ }^{3}$ Benirschke, K, Obstetrics and Gynecology, 1961, 18, 334.

${ }^{4}$ Weinberg, W, Pflügers Archiv für die gesamte Physiologie, 1902, 88, 346.

${ }^{5}$ Fredrick, J, and Anderson, A B M, British fournal of Obstetrics and Gynaecology, 1976, 83, 342.

${ }^{6}$ Butler, N R, and Alberman, E D, editors, in Perinatal Problems: Perinatal Mortality Survey, p 140. Edinburgh, Livingstone, 1969.

' Barter, R, American fournal of Obstetrics and Gynecology, 1963, 91, 784.

${ }^{8}$ Lowe, C R, and Record, R G, British fournal of Sociological Medicine, $1951,5,34$.

(Accepted 22 April 1977)

\title{
Mood changes in puerperium, and plasma tryptophan and cortisol concentrations
}

\author{
S L HANDLEY, T L DUNN, J M BAKER, C COCKSHOTT, S GOULD
}

British Medical fournal, 1977, 2, 18-22

\begin{abstract}
Summary
Eighteen women aged 18-31 years were studied daily during the second to fifth postpartum days to assess mood changes and plasma tryptophan and cortisol concentrations. Psychiatric rating scales, clinical interviews; and published biochemical methods were used. Over the period plasma free tryptophan concentrations tended to rise and plasma cortisol concentrations to decline. There was a positive correlation between plasma free tryptophan concentrations and mood state.
\end{abstract}

\section{Introduction}

Puerperal depression has received increasing attention during the past few years, and Yalom et al estimated that up to $70 \%$ of mothers have the "four-day blues." upsets occur at a time of profound biochemical changes, the puerperium may be an appropriate model for investigating possible links between biochemistry and affect. Depressive illness may be related to a functional deficiency of 5-hydroxytryptamine $(5-\mathrm{HT}) .{ }^{2-4}$ The rate of brain $5-\mathrm{HT}$ synthesis may depend at least in part on the concentration of tryptophan in the plasma, ${ }^{5}$ particularly the fraction not bound to albumin. ${ }^{6}$ Plasma free tryptophan concentrations, however, may be lowered, ? raised, ${ }^{8}$ or unchanged ${ }^{9}$ in depressive illness. Stein et al recently found that on day 6 post partum free plasma tryptophan concentrations were significantly reduced in patients with the most severe depression. ${ }^{10}$

Cortisol, on the other hand, may be increased during depressive illness. ${ }^{11-13}$ During the early puerperium this hormone declines rapidly from the peak concentrations attained

University of Aston, Birmingham B4 7ET

S L HANDLEY, BPHARM, PHD, lecturer in pharmacology

J M BAKER, BSP, PHD, research fellow

S GOULD, BSC, MPS, research assistant

Walsgrave Hospital, Coventry CV2 2DX, and Central Hospital, Warwick CV35 7EE

T L DUNN, FRCPSYCH, FRCPGLAS, consultant psychiatrist

C COCKSHOTT, MB, CHB, part-time registrar in psychiatry during labour. ${ }^{14}$ Moreover, cortisol can affect the availability of brain 5 -HT in several ways. ${ }^{15} 16$

In this preliminary study we examined the relation between plasma cortisol concentrations, free and bound tryptophan concentrations, and emotional state during the days immediately after childbirth to try to clarify the means by which mood changes occur in the puerperium.

\section{Patients and methods}

Over a four-week period women presenting to the maternity unit were considered for the study provided they were UK-born, aged 18-31 years, had given birth to live infants, and were willing to cooperate. Eighteen women fulfilled these criteria and were accepted serially. A standard, low-protein breakfast was given each morning, and drugs known to interfere with tryptophan binding were avoided. ${ }^{17}$ Samples of venous blood $(10 \mathrm{ml})$ were obtained daily between 0900 and 0930 and the plasma was analysed for cortisol, total tryptophan, and free tryptophan according to published methods. ${ }^{18-21}$ The patients were studied during the second to fifth "obstetric days," the day of parturition being regarded as day 0 if birth occurred after 1200 and as day 1 if it occurred before 1200 .

Three self-rating scales were used for quantitative psychiatric assessment. These were administered immediately after blood sampling. The Multiple Affect Adjective Check List (MAACL), ${ }^{22}$ which includes scales for depression, anxiety, and hostility, was used daily. The Beck Depression Inventory ${ }^{23}$ with the modification of Pichot $e t a l^{24}$ was also used to detect depression, and the Hildreth Feeling Scale ${ }^{25}$ to detect elation or mania, or both. These last two scales were used twice. A brief clinical interview was carried out each day on completion of the rating scales. The study was blind in that the biochemical results were unknown to the clinician performing the psychiatric assessment, and the scores for the rating scales were not computed until the end of the study.

\section{Results}

The table shows the mean biochemical values for the 18 women. Plasma cortisol steadily declined over the period, whereas the total plasma tryptophan concentration tended to rise, as did the percentage of free tryptophan. Consequently the absolute concentration of free tryptophan also rose.

None of the women was diagnosed as suffering from depressive illness at clinical interview. Three, however, exhibited elevation of mood throughout their stay, but this was not judged by the interviewer to be clinical hypomania. The figure shows the mean scores obtained on the psychiatric rating scales each day. Data for the three women showing consistent elevation of mood are plotted separately and show that for these women the Beck-Pichot scores were zero throughout. 
Mean $( \pm S E)$ plasma concentrations of cortisol and total and free Tryptophan during obstetric days $2-5$

\begin{tabular}{c|c|c|c}
\hline \multirow{2}{*}{$\begin{array}{c}\text { Obstetric } \\
\text { day }\end{array}$} & $\begin{array}{c}\text { Cortisol } \\
(\mathrm{nmol} / \mathrm{l})\end{array}$ & \multicolumn{2}{|c}{ Tryptophan $(\mu \mathrm{mol} / \mathrm{l})$} \\
\cline { 2 - 3 } & & Total & Free \\
\hline 2 & $1234 \pm 271$ & $42 \cdot 6 \pm 4 \cdot 1$ & $6 \cdot 9 \pm 1 \cdot 4$ \\
3 & $809 \pm 91$ & $47.9 \pm 3 \cdot 0$ & $8 \cdot 0 \pm 0.7$ \\
4 & $729 \pm 83$ & $47 \cdot 8 \pm 2 \cdot 8$ & $7.9 \pm 0 \cdot 5$ \\
5 & $643 \pm 44$ & $50 \cdot 2 \pm 2 \cdot 9$ & $9 \cdot 0 \pm 0 \cdot 7$ \\
\hline
\end{tabular}

Conversion: SI to traditional units-Plasma cortisol: $1 \mathrm{nmol} / 1 \approx 0.036 \mu \mathrm{g} / 100 \mathrm{ml}$ Plasma tryptophan: $1 \mu \mathrm{mol} / 1 \approx 0 \cdot 2 \mu \mathrm{g} / \mathrm{ml}$.
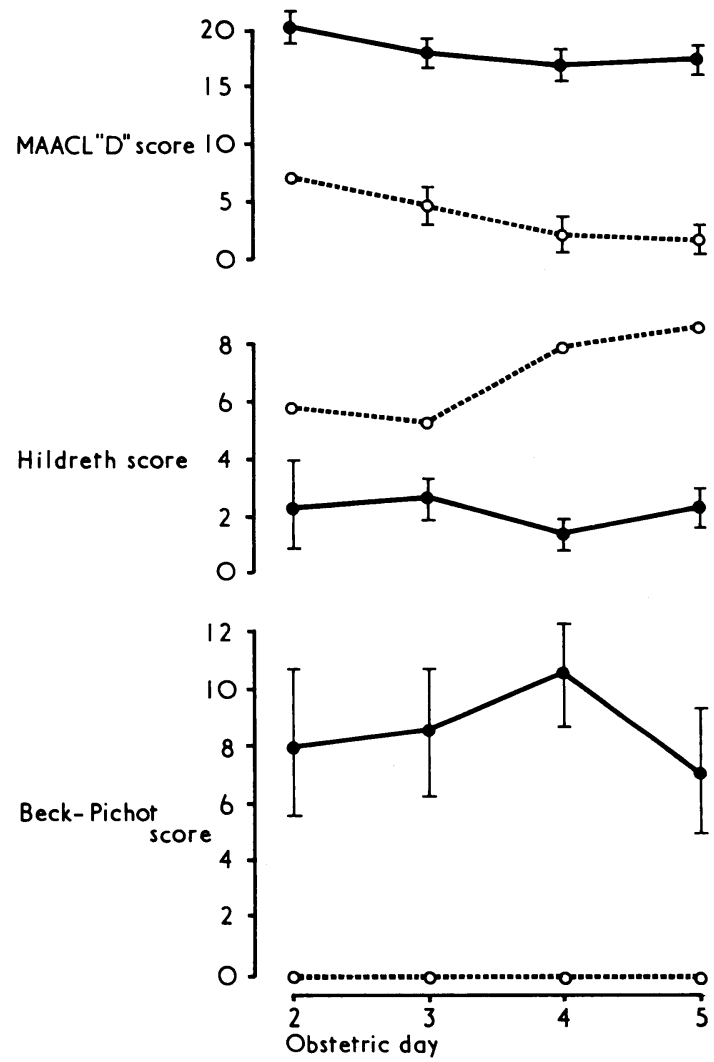

Variation in mean scores $( \pm S E)$ on psychiatric rating scales for obstetric days $2-5$. Open circles represent patients with greatly elevated mood. Closed circles represent all other patients.

The MAACL "D" (depression) scores were significantly lower and the Hildreth scores significantly higher than those for the remainder of the patients: MAACL " $A$ " (anxiety) and " $H$ " (hostility) scores were also significantly lower $(P<0.001$ in all cases; Mann-Whitney $U$ test). Biochemically the three women were distinguished by unusually high cortisol concentrations on day 2 (over $1932 \mathrm{nmol} / \mathrm{l}$ $(70 \mu \mathrm{g} / 100 \mathrm{ml})$ compared with an average of $828 \mathrm{nmol} / 1(30 \mu \mathrm{g} / 100 \mathrm{ml})$ for the rest of the patients).

The relation between the biochemical values and scores on the mood-rating scales was investigated by regression analysis. Spearman's rank correlation coefficient was used because of the non-parametric nature of the rating-scale data. These analyses were performed for all patients for all days and checked by plotting scattergrams to ensure that significant associations were not due to outlying points.

Plasma free tryptophan concentration showed a significant negative correlation with the MAACL depression score $(r=-0.30 ; P<0.01)$ and a significant positive correlation with the Hildreth (elation) score $(\mathrm{r}=+0.31 ; \mathrm{P}<0.05)$. Plasma cortisol was also positively correlated with the Hildreth score $(r=+0.35 ; P<0.05)$. Cortisol concentrations were not related to anxiety as measured by the MAACL " $A$ " scale, nor was there any significant correlation between cortisol and either free or total tryptophan concentrations.

We found that the concentration of free tryptophan correlated with total tryptophan $(\mathrm{r}=+0.75 ; \mathrm{P}<0.005)$ but not with the percentage of free tryptophan, suggesting that albumin binding was below saturation levels. When albumin binding sites are not saturated the concentration of tryptophan free in the plasma varies with changes in the total tryptophan concentration, but the percentage of the total in the free state remains constant, being determined by the binding constant of albumin.

\section{Discussion}

Clinical depression was not diagnosed in any of these 18 women, although mood changes of a depressive nature were detected at interview, and these changes were reflected in the rating-scale data. A major difficulty with a study of this kind lies in obtaining a quantitative estimate of mood that is valid for a population not already diagnosed as suffering from depressive illness. While there are many rating scales useful for assessing psychiatric patients, few can be applied to a normal population with any degree of confidence. The MAACL is useful in this respect because it embraces normal mood. The Beck-Pichot and Hildreth scales both showed a restricted range of scores, as expected, since they are designed to quantify clinical depression and elation or mania or both respectively. Nevertheless, these scores varied enough for regression analyses to be performed against the biochemical data.

A significant positive correlation was detected between free tryptophan concentration and mood. Interestingly, this extended to elevation as well as depression of mood. Stein $e t a^{10}$ recently described one patient (out of 18) who appeared to be hypomanic after childbirth but had a low plasma free tryptophan concentration. The three patients showing "puerperal elation" in this study were not judged to be hypomanic and may therefore not be comparable to such a patient. Our finding that a low free tryptophan concentration was associated with depression of mood confirms the work of Stein et al, who detected a similar relation.

Cortisol concentrations rise during labour, probably due to the oestrogen-induced rise in transcortin. ${ }^{26}$ The highest values occur at parturition, mainly as free cortisol. ${ }^{26}$ Our data, like that of Migeon $e t a l,{ }^{14}$ suggest that plasma cortisol has usually fallen to normal values by the third day post partum. The relation between cortisol and mood state does not appear to have been studied previously in patients not diagnosed as mentally ill. Cortisol concentrations have been reported to be high in depressed patients, and Hullin et al ${ }^{12}$ showed them to return to normal in the manic phase in two manic-depressed patients. It was therefore surprising that in the puerperal women studied here plasma cortisol appeared to be positively correlated with a degree of elevation of mood. This finding deserves further investigation.

Hence significant correlations may indeed occur between the biochemical variables measured and mood state in the early puerperium. Moreover, these associations were detectable even in the absence of clinically overt depressive or hypomanic illness. Mood changes in the early puerperium may thus be a useful model for studying relations between biochemical changes and mood state. An extension of this work to include antenatal and later postpartum data on a larger sample is underway to permit the investigation of temporal relations between the biochemical variables and alterations in mood.

Our thanks are due to $\mathrm{Mr} \mathrm{J}$ Marcus, $\mathrm{Mr}$ W J R Anderson, and Mr M Reid, of Walsgrave Maternity Hospital, for allowing us to study their patients; the ward staff for their help; Mr A Edington for help with the rating scales; and the research committee of the West Midlands Regional Health Authority for encouragement and financial support.

\section{References}

1 Yalom, I D, Lunde, D T, and Moos, R H, Archives of General Psychiatry, 1968, 18, 16. 
2 Lapin, I P, and Oxenkrug, G F, Lancet, 1969, 1, 132.

3 Kety, S, Advances in Behavioural Biology, 1971, 4, 237.

4 Van Praag, H M, and Korff, J, Pharmakopsychiatrie, 1975, 8, 322.

5 Fernstrein, J D, and Wurtman, B J, Science, 1971, 175, 149.

${ }^{6}$ Knott, P J, and Curzon, G, Nature, 1972, 239, 452.

7 Coppen, A, Eccleston, E G, and Peet, M, Lancet, 1972, 2, 1415.

${ }^{8}$ Niskanen, P, et al, British fournal of Psychiatry, 1976, 128, 67.

${ }^{9}$ Peet, M, et al, British fournal of Psychiatry, 1976, 128, 255.

10 Stein, G, et al, British Medical fournal, 1976, 2, 457.

11 Board, F, Wadeson, R, and Persky, H, Psychosomatic Medicine, 1957, 18, 324.

12 Hullin, R P, et al, British fournal of Psychiatry, 1967, 113, 593.

13 Sachar, E J, et al, Archives of General Psychiatry, 1973, 29, 19.

${ }^{14}$ Migeon, C J, Prystowsky, M, and Grumbach, M M, Fournal of Clinical Investigation, 1956, 35, 488.

15 Curzon, G, in Enzyme Induction, ed D V Parke, p 169. New York, Plenum, 1975.

${ }^{16}$ Neckers, L, and Sze, P Y, Brain Research, 1975, 93, 123.
17 Aylward, M, and Maddock, M, Lancet, 1973, 1, 936.

18 Mattingley, D, fournal of Clinical Pathology, 1962, 15, 374.

19 Denckla, W D, and Dewey, D K, Fournal of Laboratory and Clinical Medicine, 1967, 69, 160.

${ }^{20}$ Bloxam, D L, and Warren, W H, Analytical Biochemistry, 1974, 60, 621.

21 Bender, D A, Boulton, A P, and Coulson, W J, Biochemical Society Transactions, 1975, 3, 193.

${ }^{22}$ Zuckerman, M, and Lubin, B, Educational and Industrial Testing Service. San Diego, California, 1965

${ }^{23}$ Metcalf, M, and Goldman, E, British fournal of Psychiatry, 1965, 111, 240.

24 Pichot, J, Pret, J, and Clyde, D J, Revue de Psychologie Appliquée, 1966, 16, 105.

${ }^{25}$ Hildreth, H M, fournal of Clinical Psychology, 1946, 2, 214.

26 Sandberg, A A, et al, in Steroid Dynamics, ed G Pincus et al, p 1. New York, Academic Press, 1966.

(Accepted 22 April 1977)

\section{SHORT REPORTS}

\section{Tongue deviation and Bell's palsy}

One of the clinical signs which may be associated with Bell's palsy is deviation of the tongue. We report two cases in which this sign was evident, and discuss the aetiology.

\section{Case histories}

Case 1-A fit 32-year-old Caribbean woman attended King's College Hospital complaining of pain in the left side of the face, associated with a mild sensory disturbance of the left facial skin, of 10 days' duration. A weakness of the left facial muscles had suddenly occurred six days previously. She had an obvious left seventh nerve paralysis of a lower motor neurone type. The facial skin was tested for pain sensation (with a pin) and for fine touch perception (with cotton-wool), but no objective loss could be detected. She was aware of an alteration in taste sensation and hyperacusis. The external ear was normal and no intraoral vesicles were present to suggest a herpetic cause of the lesion. When the tongue was protruded there was a deviation to the right (figure), but she could exercise a full range of movements when commanded, there being no sign of muscle weakness. Normal proprioception was present when tested by the observer. Bell's palsy was diagnosed, and a course of prednisone, $60 \mathrm{mg}$ a day reducing over 10 days, prescribed. She made a full recovery within one month.

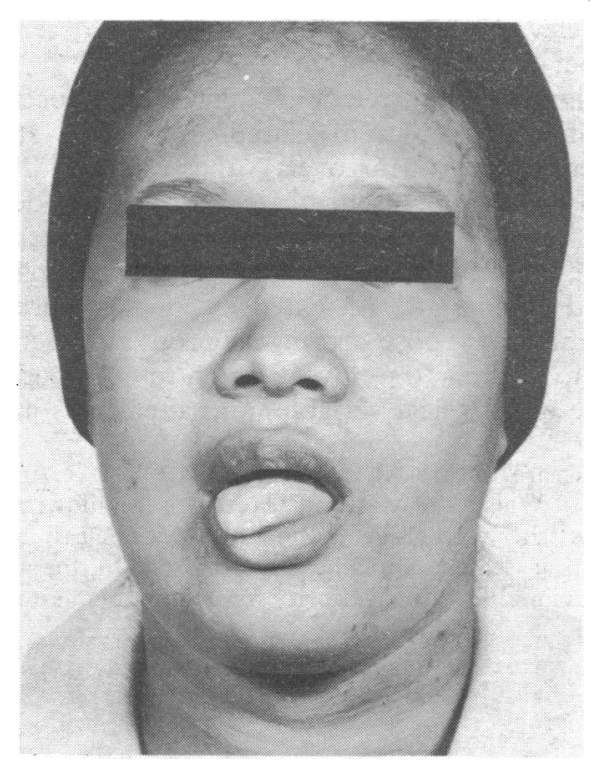

Patient with left facial nerve weakness exhibiting deviation of the tongue to the right.
Case 2-A 30-year-old Caucasian man was examined three days after the onset of a profound left-sided facial weakness, which, like the previous case, had all the characteristics of a Bell's palsy, including diminution of taste. On protrusion his tongue also deviated to the contralateral side.

\section{Comment}

Bell's palsy is a facial paralysis of acute onset due to nonsuppurative inflammation of the facial nerve within the stylomastoid foramen. Deviation of the tongue has been described as one of the features of the disorder, ${ }^{1}$ but this has recently been denied. ${ }^{2}$ In the cases reported there was a considerable displacement of the tongue on protrusion, which simulated a contralateral hypoglossal nerve palsy, but without detectable muscle weakness.

There has been much discussion about the sensory pathways of proprioceptive impulses from the tongue. The chorda tympani, ${ }^{3}$ lingual, glossopharyngeal, and hypoglossal nerves have all been suggested as carrying these. Nevertheless, ataxia of the tongue after trigeminal section will recover, ${ }^{4}$ and patients with bilateral lingual local anaesthetic blocks have shown no proprioceptive deficit. ${ }^{5}$

Both patients appeared to have lesions of the chorda tympani, as suggested by their disturbance in taste. Furthermore, the transient spontaneous contralateral deviation of the tongue indicated a mild ataxia, although on detailed examination all movements were controlled. Thus we might conclude that the chorda tympani makes some contribution to the position sense of the tongue. An alternative explanation is that this deviation is due to the tongue's being protruded "centrally" within a displaced oral aperture. Against the latter proposition is that lingual deviation soon disappeared, although the facial asymmetry persisted.

Deviation of the tongue therefore may be a clinical feature of Bell's palsy which is evident for only a short time after its onset, and to elicit this sign the patient must be requested to gently protrude the tongue. Other proprioceptive pathways appear to compensate rapidly for this deficit, which explains why the lingual anomaly is not a wellrecognised feature of the syndrome.

${ }^{1}$ Brain, W R, and Walton, J N, editors, Brain's Diseases of the Nervous System, 7th edn. London, Oxford University Press, 1969.

2 Warwick, R, and Williams, P L, editors, Gray's Anatomy, 35th edn. London, Longman, 1973.

3 Langworthy, O R, Fournal of Comparative Neurology, 1923, 36, 273.

4 Rowbotham, G F, Brain, 1939, 62, 364.

5 Adatia, A K, and Gehring, E N, British Dental fournal, 1972, 133, 377.

(Accepted 23 March 1977)

Department of Oral and Maxillofacial Surgery, King's College Hospital Dental School, London SE5 8RX

M HARRIS, MB, FDSRCS, consultant

J P ROOD, MB, FDSRCs, senior lecturer 